\section{Grandes Obras na Amazônia: Engajando Atores
Sociais para Promover o Desenvolvimento \\ Grandes Obras na Amazônia: Engajando Atores
Sociais para Promover o Desenvolvimento Sustentável} Large-Scale Projects in the Amazon: Engaging Social Actors to Promote
Sustainable Development Large-Scale Projects in the Amazon: Engaging Social Actors to Promote
Sustainable Development

\author{
Thomaz Wood Jr. ${ }^{1 \oplus}$ \\ Dafne Oliveira Carlos de Morais ${ }^{2}$
}

No dia 29 de março de 2017, Daniela Gomes Pinto, Hector Gomez Ang e os demais membros do projeto Grandes Obras na Amazônia - Aprendizados e Diretrizes se reuniram para divulgar o resultado de 18 meses de intenso trabalho. $\mathrm{O}$ projeto foi criado com o objetivo de ajudar a quebrar um dos paradoxos que caracterizam a região amazônica: a região é uma das mais ricas do mundo em biodiversidade e recursos naturais, e uma das mais pobres do Brasil em termos de desenvolvimento econômico e social.

Durante esse período, a equipe, que somava 17 profissionais do Centro de Estudos de Sustentabilidade da Fundação Getulio Vargas (FGVces) e da International Finance Corporation (IFC), dialogou com dezenas de partes interessadas: grandes empresas de engenharia e construção, organizaçōes sociais, órgãos governamentais, representantes de quilombolas, populaçóes ribeirinhas e povos indígenas. $\mathrm{O}$ objetivo foi organizar e evidenciar liçóes aprendidas e recomendaçóes, no âmbito das políticas públicas e das

\footnotetext{
1. Fundação Getulio Vargas, Escola de Administração de Empresas de São Paulo (FGV EAESP), São Paulo, SP, Brasil.

2. Centro Universitário FEl, São Paulo, SP, Brasil.
}

Como citar: Wood, T., Jr., \& Morais, D. O. C. (2021). Grandes obras na amazônia: Engajando atores sociais para promover o desenvolvimento sustentável. Revista de Administração Contemporânea, 25(3), e200053. https://doi.org/10.1590/1982-7849rac2021200053.por

\# de revisores convidados até a decisão: práticas empresariais, que estabelecessem um novo tipo de relação entre grandes empreendimentos e os territórios que os abrigam.

Em um auditório do Hotel Radisson, em Belém, Daniela, do FGVces, e Hector, da IFC, comentam otimistas as realizaçóes e conquistas do projeto. Enquanto aguardam começar o evento de encerramento da fase final do projeto, relembram como foi árduo o processo de engajar atores sociais com interesses táo dissonantes. Daniela reflete sobre os longos meses de trabalho e os dilemas do projeto. Avalia se a tecnologia social adotada para engajar as partes interessadas terá sido suficiente para garantir o sucesso na implantação das diretrizes e o que poderá ainda ser feito para ajudar a atingir esse objetivo. O sucesso na implantação das diretrizes pode ser um divisor de águas para o desenvolvimento sustentável da Amazônia, com fortes impactos sobre as populaçóes locais e o equilíbrio ecológico da regiâa, com repercussóes que transcendem o Brasil. Resta o desafio de garantir tal sucesso.

\begin{tabular}{|c|c|c|c|c|c|c|c|c|c|}
\hline & 1 & 2 & 3 & 4 & 5 & 6 & 7 & 8 & 9 \\
\hline $1^{a}$ rodada & $\sum^{\infty}$ & (x) & $\stackrel{8}{2}$ & & & & & & \\
\hline $2^{a}$ rodada & & $\frac{9}{2}$ & & & & & & & \\
\hline $3^{a}$ rodada & 2 & & & & & & & & \\
\hline $4^{a}$ rodada & $\stackrel{0}{2}$ & & & & & & & & \\
\hline
\end{tabular}




\section{AMAZÔNIA}

A Amazônia é frequentemente caracterizada por superlativos: a maior biodiversidade em uma floresta tropical da Terra, a maior bacia hidrográfica do mundo e a maior concentraçáo de espécies terrestres do planeta. São quase sete milhôes de quilômetros quadrados, que ocupam sete estados brasileiros e cinco países da América Latina, além do Brasil. Cerca de $60 \%$ da bacia amazônica localiza-se em território brasileiro. Essa bacia contém aproximadamente um quinto do volume de água doce do planeta. Em suas margens, habitam quatro milhóes de pessoas, entre elas indígenas, ribeirinhos e quilombolas.

A exploração de recursos naturais da Amazônia pode gerar benefícios substantivos. A concentraçáo de recursos naturais nessa vasta regiáo atrai organizaçóes públicas e privadas. Essas organizaçóes se interessam por seu potencial de abrigar grandes empreendimentos, tais como a construção de hidrelétricas, a instalação de plantas de mineração e a implantação de centros de distribuição e logística.

Por outro lado, ações na Amazônia podem influenciar o regime de chuvas no Brasil e em outros países da América do Sul. A região é considerada fundamental para a manutenção do equilíbrio climático global.

Grandes obras geram consideráveis impactos socioambientais: desmatamento, poluição, deslocamentos de populaçóes, violação de direitos humanos, alteração de modos de vida, e demandas extraordinárias sobre serviços básicos de saúde e educação. Esses impactos atingem uma regiáo vulnerável e pouco desenvolvida.

A Amazônia vem há muitos anos ocupando um lugar de destaque na agenda ambiental mundial. Notícias sobre queimadas e disputas por terra são frequentemente veiculadas pelos principais órgãos mundiais de imprensa, tais como The New York Times, The Economist, The Guardian, Le Monde, El Pais e Der Spiegel.

Recentemente, o quadro na regiáo parece ter se agravado. Entre os meses de agosto de 2019 e julho de 2020, o INPE - Instituto Nacional de Pesquisas Espaciais registrou aumento de $34 \%$ no desmatamento. Tal condiçáo torna ainda mais urgentes medidas que enderecem as raízes dos problemas que afetam a Amazônia.

\section{EXPERIÊNCIAS ANTERIORES NA REGIÃO AMAZÔNICA}

A Amazônia tem sido foco de trabalho do FGVces e da IFC há tempo. O projeto "Grandes Obras na Amazônia: Aprendizados e Diretrizes" integra o Programa Desenvolvimento Local, coordenado por Daniela, que atua há mais de 15 anos junto a obras de infraestrutura e mineraçáo, e com indicadores de monitoramento do desenvolvimento local. O projeto foi iniciado em 2015 e segue outros três projetos também realizados pelo FGVces na Amazônia.

$\mathrm{O}$ primeiro projeto ocorreu na região que hospedou uma planta de mineração em Juruti, no Pará. Em 2006, a mineradora norte-americana Alcoa solicitou ao FGVces e ao Fundo Brasileiro para a Biodiversidade (Funbio) a elaboração de um plano que viabilizasse o desenvolvimento sustentável, considerando as profundas transformaçóes sociais, econômicas e ambientais a serem vividas com a chegada do empreendimento. O resultado desse trabalho foi o modelo Juruti Sustentável, e em seguida a construção participativa de uma ferramenta de indicadores de desenvolvimento, para mensurar as transformaçóes da localidade afetada.

O segundo projeto foi na regiáo que recebeu a hidrelétrica de Jirau, no Rio Madeira, em Rondônia. Em 2008, a empresa Energia Sustentável do Brasil (ESBR) procurou o FGVces para desenvolver um projeto que garantisse que a obra deixasse um legado positivo para a regiâo. A ESBR desejava implantar um polo industrial junto à hidrelétrica. Durante o ano de 2009, o FGVces realizou um diagnóstico e elaborou um plano de desenvolvimento regional, no qual apontou oportunidades voltadas para economia florestal e madeira certificada. $\mathrm{O}$ plano náo se concretizou, porém ocorreu uma busca pela internalizaçáo da proposta, materializada em compromissos em longo prazo da ESBR.

$\mathrm{O}$ terceiro projeto foi para a regiáo que recebeu a hidrelétrica de Belo Monte, no Pará. A usina é um dos maiores projetos hidrelétricos do mundo e representa o ápice de uma trajetória de controvérsias envolvendo grandes empreendimentos na Amazônia e as sociedades locais. Nesse projeto, o FGVces desenvolveu uma ferramenta de monitoramento de condicionantes do licenciamento ambiental.

Avaliando todas essas experiências, Daniela e seus colegas concluíram que "existia uma grande desconexão entre o planejamento e a implantação dos projetos, considerando suas demandas sociais locais ... também ficou claro que não havia mecanismos para consolidar boas práticas $\mathrm{e}$ aprendizados relacionados à gestáo do desenvolvimento local"; ou seja, além das práticas e dos aprendizados serem escassos, mesmo quando presentes, não eram sistematizados para uso futuro.

Daniela e seus colegas também perceberam problemas sistêmicos, tais como: mau uso dos recursos financeiros, descompasso entre geração de receita e necessidades e falta de clareza quanto a papéis e responsabilidades. Aquele foi o momento em que decidiram como seriam os próximos passos de sua atuação na regiáo. 
Daniela e Hector perceberam que mais um projeto focado em uma grande obra não seria suficiente para diminuir os impactos socioambientais da região. Eles precisavam garantir que todas as obras já partissem de um planejamento de mitigação de danos sociais e ambientais.

Segundo Daniela, "Queríamos colocar em debate os erros que vinham se repetindo. Então, decidimos organizar nosso conhecimento, reunir o conhecimento dos atores envolvidos no contexto amazônico e pensar em soluçóes para que esses erros parassem de se reproduzir".

Para Hector, "Era preciso mudar e entramos nesse processo porque precisávamos fazer parte dessa conversa ... mas percebemos que não havia uma conversa articulada sobre o tema; existia um ofício indo e voltando, não uma conversa robusta, que considerasse todos os envolvidos. Foi preciso criar essa conversa, tentando não reinventar os elementos que já existiam, incorporando o que havia a respeito e organizando tudo para criar coisas novas".

Com essa visão em mente, Daniela e sua equipe deram início ao novo projeto, em parceria com a IFC, liderada por Hector.

\section{O PROJETO "GRANDES OBRAS NA AMAZÔNIA: APRENDIZADOS E DIRETRIZES"}

O FGVces foi criado em 2003 e é um dos 18 centros de pesquisa aplicada da Escola de Administração de Empresas de São Paulo, da FGV. O centro trabalha no desenvolvimento de estratégias, políticas e ferramentas de gestão públicas e empresariais para a sustentabilidade, no âmbito local, nacional e internacional. Contava, no início de 2017, com mais de 60 pesquisadores e com cerca de 80 organizaçóes parceiras, incluindo empresas privadas, organizaçóes sociais, fundaçóes, institutos, secretarias públicas e universidades.

A IFC, por sua vez, foi criada em 1956 e faz parte do Banco Mundial, uma das maiores fontes de financiamento para países em desenvolvimento. A IFC atua em mais de 100 países em desenvolvimento, apoiando o setor privado no combate à miséria e busca da prosperidade. A organização presta assistência por meio de produtos financeiros, como participaçóes de capital social e empréstimos de longo prazo, e de serviços de assessoria. O Brasil tem recebido parcela representativa dos investimentos da IFC.

Buscando soluçôes para impactos negativos provocados pela realização de grandes empreendimentos, o FGVces e a IFC conceberam o projeto "Grandes Obras na Amazônia: Aprendizados e Diretrizes". Daniela, coordenadora do projeto no FGVces, apoiou-se em sua experiência anterior na região para definir o escopo do projeto. Com sua equipe, identificou dois objetivos: evitar impactos socioambientais negativos das grandes obras na região e criar um guia de melhores práticas para reduzir tais impactos.

Para fazer frente à complexidade do projeto, foram aplicadas diversas práticas de tecnologia social. Segundo Daniela, "as questóes centrais do projeto foram desdobradas em seis linhas de ação, cada uma com o seu próprio grupo de trabalho responsável". As seis linhas de ação definidas foram as seguintes: (1) planejamento e ordenamento territorial; (2) capacidades institucionais; (3) instrumentos financeiros; (4) direitos humanos dos povos indígenas, comunidades tradicionais e quilombolas; (5) direitos humanos das crianças, adolescentes e mulheres; e (6) supressão vegetal autorizada.

As atividades dos grupos de trabalho tiveram início em outubro de 2015 e se estenderam por 18 meses. De acordo com Daniela, "para facilitar a troca de experiências e informaçóes entre a extensa rede de atores envolvidos, cada grupo promoveu eventos no âmbito de sua temática. Foram mais de 180 organizaçóes e mais de 480 pessoas que participaram dos trabalhos conosco".

Um desafio enfrentado pela equipe foi desenhar uma metodologia nova, com um escopo maior, e diferente daquela aplicada em projetos anteriores. Para Daniela, "tínhamos em mente que não se tratava mais de propor diagnósticos e soluçóes para uma localidade que receberia um empreendimento. Agora, o trabalho voltava-se para mapear impactos nas dimensóes social, ambiental e econômica na perspectiva de múltiplos atores sociais, gerir demandas e vozes de diferentes partes interessadas - muitas vezes, conflitantes - e, ainda, engajá-las, visando a organizar liçóes aprendidas e elaborar recomendaçóes, no âmbito público e privado”.

Considerando esse escopo amplo e desafiador, foram planejadas quatro etapas. A "primeira etapa" - sistematização do conhecimento - buscou organizar o conhecimento acumulado sobre cada um dos seis temas dos grupos de trabalho. Para isso, foram realizadas duas reunióes de consulta prévia, com cerca de 40 participantes, além de pesquisas bibliográficas e mais de 60 entrevistas. A consulta prévia comprovou a pertinência de criar diretrizes para grandes obras na Amazônia. A consolidação das discussōes gerou mais de 40 publicaçóes e relatórios, disponibilizados no website da iniciativa. Esses relatórios e documentos subsidiaram as atividades posteriores.

A "segunda etapa" - articulação e discussão - teve como objetivo articular os atores envolvidos e discutir aspectos controversos, buscando identificar pontos de convergência e facilitar o alinhamento. Os seis grupos temáticos interagiram com participantes dos setores empresarial, público, financeiro, acadêmico e da sociedade civil. De acordo com a necessidade de interação necessária para a compreensão de cada tema, os grupos de trabalho selecionaram diferentes formatos de atividades - reunióes, seminários de consulta, seminários 
temáticos e seminários participativos -, além de diferentes localidades geográficas. Ao todo, foram organizadas 18 reunióes e cinco seminários, em Altamira, Belém, Brasília e São Paulo. A premissa de participação ampla e diversificada estimulou a equipe a engajar indígenas, quilombolas e povos tradicionais em todos os grupos de trabalho. Essa medida foi crucial para a posterior disseminação do conteúdo discutido.

A “terceira etapa" - formulação de diretrizes - focalizou o desenvolvimento das diretrizes para nortear futuros empreendimentos. O conteúdo criado foi resultado das pesquisas e discussóes conduzidas pelos líderes dos seis grupos de trabalho. Além da elaboração preliminar das diretrizes, foram identificadas prioridades comuns (transversais) entre os grupos de trabalho, relacionadas a focos tais como: fortalecer a cooperação entre atores sociais, evitar o desperdício de recursos, garantir os direitos de grupos vulneráveis, e garantir a transparência do conhecimento e das informaçóes. O FGVces e a IFC também conduziram uma consulta pública, visando a coletar contribuições adicionais sobre as diretrizes formuladas. As diretrizes foram disponibilizadas no website da iniciativa (http://diretrizes-grandesobras.gvces.com.br/ recuperado em 15 de Dezembro, 2020), ao lado de todo conteúdo elaborado nas fases anteriores. Foram recebidas 45 contribuições, as quais geraram 14 alterações nas diretrizes.

A "quarta etapa" - disseminaçáo e engajamento - envolveu atividades destinadas a comunicar o trabalho realizado e a consolidar o engajamento dos atores sociais com as diretrizes, visando a facilitar sua efetiva implantaçáo. $\mathrm{O}$ FGVces e a IFC compartilharam relatórios sobre a evolução das atividades e os resultados da iniciativa. Os eventos foram planejados em múltiplos locais para contemplar participação ampla e diversificada.

\section{LANÇAMENTO DAS DIRETRIZES}

O lançamento das diretrizes foi realizado com um evento em Belém para os representantes das diversas partes interessadas que atuaram no projeto, tais como: Alcoa, Votorantim, Vale, Caixa Econômica Federal, Coordenação das Organizaçôes Indígenas da Amazônia Brasileira (Coiab), Coordenação Estadual das Associações das Comunidades Remanescentes de Quilombo do Pará, Funbio, Universidade Federal do Pará, entre dezenas de organizaçóes do setor privado, do setor público e do terceiro setor.

Daniela, Hector e as equipes de trabalho apresentaram a trajetória percorrida e as atividades que viabilizaram a elaboração das 25 diretrizes formuladas (Anexo 1). Diante da plateia, Daniela explicou que "já é possível perceber os benefícios que as diretrizes geram. Com a grande participaçáo em todas as etapas, o projeto permitiu que as partes interessadas, muitas vezes em posiçôes divergentes, interagissem em um ambiente neutro e cooperativo, distante das pressōes de um empreendimento específico. As diretrizes, os relatórios e demais produtos gerados já refletem pontos de convergência entre esses múltiplos atores envolvidos, algo muito importante para o ciclo de implementação, nosso próximo passo a ser iniciado".

Daniela também destacou que "a implementação das diretrizes trará benefícios de vários lados. Do ponto de vista empresarial, percebemos que a adoção das diretrizes pode contribuir para aumentar a previsibilidade e para reduzir riscos, fatores críticos para a implementação de grandes empreendimentos. Já em termos de benefícios sociais, a adoção das diretrizes pode contribuir para a proteção e o desenvolvimento das populaçóes, especialmente indígenas, quilombolas e ribeirinhos. Por fim, e não menos importante, em termos de benefícios ambientais, a adoção das diretrizes pode contribuir para aperfeiçoar a gestão compartilhada dos recursos naturais, algo tâo necessário na região amazônica”.

Daniela encerrou o evento reforçando mais uma vez sobre o desafio à frente: a implantação das diretrizes, indicando à plateia presente que "precisamos seguir contando com a participação de todos para que a elaboraçáo das diretrizes saia do papel e se torne realidade". Ao fim do evento, algumas empresas disponibilizaram-se para realizar projetos-piloto de aplicaçáo das diretrizes e o debate continuou sobre como seria a melhor forma de darem início a essa nova fase.

\section{PRÓXIMOS PASSOS}

Retornando para suas casas, Daniela e Hector refletem sobre o novo ciclo que se iniciará no projeto, que compreenderá a aplicação das diretrizes a novos empreendimentos na Amazônia. O principal desafio será garantir mudanças factíveis na realização dos empreendimentos, mudanças que possibilitem disseminar na prática o conhecimento gerado no ciclo anterior, articulando os vários agentes e fomentando a aplicação das diretrizes.

Além da implantação das diretrizes no Brasil, o projeto também pretende ampliar sua atuaçáo para outros países da regiấo Amazônica. Para isso, haviam sido realizados contatos no Peru e na Colômbia.

A implantação das diretrizes no Brasil e a expansão do modelo em outros países amazônicos constituem desafios que exigiráo considerável esforço. Será o momento de entender até que ponto os atores envolvidos na elaboração das diretrizes estáo de fato dispostos a se adaptar e a mudar para evitar impactos socioambientais negativos das grandes obras na região amazônica. Daniela e Hector seguem confiantes de que o aprendizado e o engajamento conseguidos constituem a base que necessitarão, porém buscam identificar o que mais poderia contribuir para garantir a continuidade do sucesso dessa iniciativa. 


\section{ANEXO 1}

Tabela A1. Diretrizes para grandes obras na Amazônia.

\begin{tabular}{|c|c|c|c|c|c|}
\hline $\begin{array}{l}\text { Planejamento e } \\
\text { ordenamento territorial }\end{array}$ & Instrumentos financeiros & $\begin{array}{l}\text { Capacidades } \\
\text { institucionais }\end{array}$ & $\begin{array}{l}\text { Povos indígenas, } \\
\text { comunidades } \\
\text { tradicionais e } \\
\text { quilombolas }\end{array}$ & $\begin{array}{c}\text { Crianças, adolescentes e } \\
\text { mulheres }\end{array}$ & $\begin{array}{l}\text { Supressão Vegetal } \\
\text { Autorizada }\left(^{*}\right)\end{array}$ \\
\hline $\begin{array}{l}\text { (1) O território deve ser } \\
\text { compreendido como } \\
\text { elemento estratégico do } \\
\text { planejamento regional } \\
\text { que subsidia a tomada } \\
\text { de decisão, a formulaçáo } \\
\text { e a execução de grandes } \\
\text { obras na Amazônia. } \\
\text { (2) Processos de } \\
\text { planejamento territorial } \\
\text { devem contar com } \\
\text { mecanismos e } \\
\text { procedimentos voltados } \\
\text { a convergências, } \\
\text { aumento das } \\
\text { capacidades, } \\
\text { financiamento adequado } \\
\text { e monitoramento } \\
\text { efetivo. } \\
\text { (3) O ordenamento } \\
\text { territorial é essencial } \\
\text { para o desenvolvimento } \\
\text { e para o planejamento } \\
\text { adequado, portanto, } \\
\text { deve ser realizado antes } \\
\text { da instalação de grandes } \\
\text { obras nos territórios } \\
\text { impactados. } \\
\text { (4) Estabelecer } \\
\text { governança com plena } \\
\text { participaçáo social } \\
\text { é imprescindível } \\
\text { aos processos de } \\
\text { planejamento e de } \\
\text { desenvolvimento } \\
\text { territorial. }\end{array}$ & $\begin{array}{l}\text { (5) Instrumentos } \\
\text { financeiros devem ser } \\
\text { guiados a atender e } \\
\text { responder a agendas } \\
\text { de desenvolvimento } \\
\text { local coletivamente } \\
\text { construídas para os } \\
\text { territórios. } \\
\text { (6) Os instrumentos } \\
\text { financeiros devem estar } \\
\text { amparados em arranjos } \\
\text { e espaços de governança } \\
\text { participativos e } \\
\text { representativos dos } \\
\text { diferentes atores } \\
\text { envolvidos. } \\
\text { (7) Instrumentos } \\
\text { financeiros devem ser } \\
\text { flexíveis e dinâmicos, } \\
\text { e estruturados } \\
\text { considerando-se } \\
\text { demandas das diferentes } \\
\text { fases de implementaçáo } \\
\text { de grandes obras. } \\
\text { (8) Instrumentos } \\
\text { financeiros devem } \\
\text { contar com estratégias } \\
\text { de aplicação de recursos } \\
\text { capazes de responder } \\
\text { à sua missão e a seus } \\
\text { objetivos, tendo em } \\
\text { vista as distintas } \\
\text { especificidades das } \\
\text { demandas e dos } \\
\text { investidores, de forma } \\
\text { a realizar investimentos } \\
\text { de maneira eficiente e } \\
\text { efetiva. } \\
\text { (9) Instrumentos } \\
\text { financeiros devem } \\
\text { ter sistema de } \\
\text { monitoramento dos seus } \\
\text { processos e resultados } \\
\text { quanto à efetividade dos } \\
\text { investimentos no alcance } \\
\text { dos objetivos. }\end{array}$ & $\begin{array}{l}\text { (10) O diagnóstico } \\
\text { das demandas e } \\
\text { o planejamento } \\
\text { das iniciativas de } \\
\text { fortalecimento } \\
\text { institucional devem ser } \\
\text { precisos, inclusivos e } \\
\text { com recursos financeiros } \\
\text { suficientes para sua } \\
\text { realização adequada. } \\
\text { (11) O fortalecimento } \\
\text { das capacidades } \\
\text { institucionais deve } \\
\text { balancear fatores } \\
\text { tangíveis e intangíveis. } \\
\text { (12) Fortalecer as } \\
\text { capacidades deve } \\
\text { incluir todos os } \\
\text { atores envolvidos, } \\
\text { reconhecendo assimetrias } \\
\text { e fomentando o diálogo. } \\
\text { (13) As rotinas de } \\
\text { participaçáo social dos } \\
\text { arranjos de governança } \\
\text { territorial são o locus } \\
\text { prioritário para auxiliar } \\
\text { a fundamentar posturas } \\
\text { institucionais relevantes } \\
\text { para os processos de } \\
\text { fortalecimento de } \\
\text { capacidades. }\end{array}$ & $\begin{array}{l}\text { (14) Estabelecer } \\
\text { processos de } \\
\text { planejamento e } \\
\text { desenvolvimento } \\
\text { territorial com } \\
\text { políticas públicas } \\
\text { específicas e medidas } \\
\text { de proteção para a } \\
\text { promoçâo do bem- } \\
\text { estar social dos povos } \\
\text { indígenas, comunidades } \\
\text { tradicionais e } \\
\text { quilombolas. } \\
\text { (15) Articular esforços } \\
\text { e investimentos para } \\
\text { melhorar a eficácia } \\
\text { e a efetividade } \\
\text { do licenciamento } \\
\text { ambiental, com } \\
\text { adequada consideraçáo } \\
\text { dos componentes } \\
\text { relativos a povos } \\
\text { indígenas, comunidades } \\
\text { tradicionais e } \\
\text { quilombolas. } \\
\text { (16) Investir no } \\
\text { aprimoramento } \\
\text { dos processos de } \\
\text { comunicação e } \\
\text { governança junto } \\
\text { a povos indígenas, } \\
\text { comunidades } \\
\text { tradicionais e } \\
\text { quilombolas, } \\
\text { utilizando canais, } \\
\text { formatos, linguagem e } \\
\text { instâncias apropriados } \\
\text { para assegurar o } \\
\text { fortalecimento de } \\
\text { sua participação no } \\
\text { planejamento e ao } \\
\text { longo da vida útil dos } \\
\text { empreendimentos. } \\
\text { (17) Garantir a } \\
\text { efetividade da consulta } \\
\text { prévia junto a povos } \\
\text { indígenas, comunidades } \\
\text { tradicionais e } \\
\text { realizada de forma } \\
\text { ampla e abrangente, } \\
\text { inclusive nos processos } \\
\text { de planejamento. }\end{array}$ & $\begin{array}{l}\text { (18) É fundamental a } \\
\text { realização de Avaliaçãoo } \\
\text { de Impacto em } \\
\text { Direitos Humanos } \\
\text { no planejamento de } \\
\text { grandes obras assim } \\
\text { como durante as fases } \\
\text { de instalaçáo e operação, } \\
\text { como medida para a } \\
\text { correta identificação } \\
\text { de vulnerabilidades e } \\
\text { riscos que oriente açóes } \\
\text { preventivas e de controle } \\
\text { por parte do Estado e } \\
\text { das empresas. } \\
\text { (19) Deve-se priorizar } \\
\text { o planejamento, } \\
\text { a instalação e o } \\
\text { funcionamento } \\
\text { continuado de } \\
\text { equipamentos sociais } \\
\text { específicos ou que } \\
\text { contemplem crianças, } \\
\text { adolescentes e mulheres } \\
\text { e que possam garantir- } \\
\text { lhes acesso a direitos e } \\
\text { serviços essenciais. } \\
\text { (20) A gestão } \\
\text { empresarial dos } \\
\text { impactos dos grandes } \\
\text { empreendimentos } \\
\text { deve priorizar a } \\
\text { prevenção, o controle } \\
\text { e o monitoramento } \\
\text { dos riscos aos direitos } \\
\text { humanos, valendo-se de } \\
\text { mecanismos de escuta e } \\
\text { indicadores capazes de } \\
\text { avaliar a qualidade das } \\
\text { medidas adotadas. } \\
\text { (21) Assegurar a } \\
\text { participação contínua } \\
\text { da sociedade civil local, } \\
\text { com o protagonismo de } \\
\text { crianças, adolescentes e } \\
\text { mulheres nos espaços de } \\
\text { decisão sobre grandes } \\
\text { empreendimentos, e } \\
\text { valorizar espaços de } \\
\text { maior mobilização desses } \\
\text { segmentos e os conselhos } \\
\text { setoriais específicos. }\end{array}$ & $\begin{array}{l}\text { (22) A } \\
\text { procedimentalização das } \\
\text { operaçóes de Supressáo } \\
\text { Vegetal Autorizada } \\
\text { deve estar respaldada } \\
\text { por orientação } \\
\text { normativa, com força } \\
\text { nos procedimentos } \\
\text { administrativos da } \\
\text { esfera pública, com foco } \\
\text { na destinaçáo e uso } \\
\text { da madeira e material } \\
\text { lenhoso suprimido. } \\
\text { (23) O planejamento } \\
\text { das açôes de Supressão } \\
\text { Vegetal Autorizada } \\
\text { deve se dar de forma } \\
\text { antecipada e com foco } \\
\text { no uso e destino dos } \\
\text { materiais suprimidos, } \\
\text { fortalecendo estudos, } \\
\text { diagnósticos e } \\
\text { orientaçóes. } \\
\text { (24) O pleno } \\
\text { aproveitamento dos } \\
\text { materiais florestais } \\
\text { oriundos de Supressão } \\
\text { Vegetal Autorizada } \\
\text { deve priorizar a } \\
\text { destinação orientada ao } \\
\text { fortalecimento de cadeias } \\
\text { florestais regionais } \\
\text { e à dinamização das } \\
\text { economias locais. } \\
\text { (25) A participação } \\
\text { e o controle social } \\
\text { nas decisóes e no } \\
\text { acompanhamento da } \\
\text { destinação dos materiais } \\
\text { oriundos de Supressão } \\
\text { Vegetal Autorizada } \\
\text { potencializam a } \\
\text { efetividade das ações } \\
\text { e minimizam custos } \\
\text { socioambientais. }\end{array}$ \\
\hline
\end{tabular}

Nota. *Este tema surgiu como desdobramento das reflexóes sobre gestáo ambiental e territorial, gerando diretrizes pontuais a partir de grupo de trabalho específico. Fonte: Adaptado de: Ang, H. G, \& Monzoni, M. (2017). Grandes obras na Amazônia: Aprendizados e diretrizes. São Paulo: FGVces \& IFC. Retrieved from https://bibliotecadigital.fgv.br/dspace/handle/10438/18320. 


\section{RESUMO}

Este caso de ensino destina-se ao uso em cursos de graduação e pósgraduação de administração pública e administração de empresas, em disciplinas que tratem do tema sustentabilidade. Podem ser trabalhados os seguintes tópicos: desenvolvimento sustentável, tripé da sustentabilidade, gestão de partes interessadas e engajamento de atores sociais. O caso narra como o FGVces (Centro de Estudos de Sustentabilidade, da FGV Eaesp) e a IFC (International Finance Corporation, do Banco Mundial) realizaram um projeto voltado para o desenvolvimento sustentável da Amazônia. O resultado foi a criação de 25 diretrizes para a realizaçáo de grandes obras na região. $\mathrm{O}$ caso foca o término da primeira fase, momento no qual os líderes do projeto refletem sobre o caminho percorrido e o desafio para implementaçáo das diretrizes. Sua discussáo permite aos estudantes imergir nos dilemas relacionados ao desenvolvimento sustentável, discutir os desafios relacionados à conduçáo de um projeto que envolve múltiplas partes interessadas, e refletir sobre a melhor forma de implantaçáo. $\mathrm{O}$ objetivo é que os estudantes incorporem a premissa de desenvolvimento sustentável às suas decisóes, e que sejam capazes de identificar os dilemas inerentes à materialização deste conceito e de analisar prós e contras de diferentes caminhos.

Palavras-chave: desenvolvimento sustentável; Amazônia; engajamento de atores sociais; gestão de partes interessadas.

\section{OBJETIVOS EDUCACIONAIS}

Este caso foi desenvolvido para proporcionar uma discussão estruturada sobre como o conceito de desenvolvimento sustentável pode se manifestar na prática. $\mathrm{O}$ caso permite que os estudantes: primeiro, reconheçam os três pilares (econômico, social e ambiental) do desenvolvimento sustentável; segundo, analisem criticamente trade-offs entre benefícios econômicos e benefícios socioambientais; terceiro, reconheçam a necessidade de engajar atores sociais com interesses conflitantes para promover um equilíbrio entre benefícios econômicos e socioambientais; e, quarto, discutam alternativas para gerir partes interessadas, considerando suas demandas econômicas, sociais e ambientais.

\section{TEMAS CENTRAIS}

Este caso permite abordar três temas centrais: (a) tripé da sustentabilidade; (b) gestáo de partes interessadas;e (c) Engajamento de atores sociais.

\section{ABSTRACT}

This teaching case is intended for use in undergraduate and graduate courses in public administration and business administration, in subjects that deal with the theme of sustainability. The following topics can be worked on: the triple bottom line, sustainable development, stakeholder management, and engagement of social actors. The case narrates how FGVces (Center for Sustainability Studies, from FGV Eaesp) and IFC (International Finance Corporation, from the World Bank) carried out a project aimed at the sustainable development of the Amazon. The result was the creation of 25 guidelines for the execution of large projects in the region. The case focuses on the end of the first phase, at which point the project leaders reflect on the path taken and the challenge for implementing the guidelines. Its discussion allows students to immerse themselves in dilemmas related to sustainable development, discuss the dilemmas and challenges related to conducting a project that involves multiple stakeholders, and reflect on the best form of implementation. The objective is for the students to incorporate the premise of sustainable development in their decisions, to be able to identify the dilemmas inherent to the materialization of this concept, and to weigh the pros and cons of different pathways.

Keywords: sustainable development; Amazon; engagement of social actors; stakeholders' management.

\section{PÚBLICO-ALVO}

Sustentabilidade é um tema transversal, de importância crescente frente aos desafios econômicos, sociais e ambientais que o mundo enfrenta. Este caso pode ser utilizado em cursos de graduação e pós-graduação em administração pública. Pode, também, com adaptaçóes, ser utilizado em cursos de graduação e pós-graduação em administração de empresas. Seguem exemplos de disciplinas que podem utilizar o caso: (a) Sustentabilidade; (b) gestão socioambiental; (c) responsabilidade social corporativa; (d) gestão de projetos; (e) políticas públicas.

\section{PREPARAÇÃO DO ESTUDANTE}

O caso pode ser aplicado para discussão dos três temas centrais citados. $\mathrm{O}$ instrutor pode utilizar o caso para estimular debates com maior foco em um dos temas, caso disponha de restrição de tempo. Entretanto, recomenda-se que os três temas sejam abordados conjuntamente. 
Para facilitar a discussão inicial com foco no tripé da sustentabilidade, o instrutor pode contextualizar para os estudantes o conceito de desenvolvimento sustentável. $\mathrm{O}$ instrutor pode ainda estimular a reflexão sobre os tradeoffs entre os pilares do tripé da sustentabilidade: econômico, social e ambiental.

O caso evidencia como um novo empreendimento pode oferecer benefícios econômicos para o país, para grandes empresas e para a comunidade, na forma de empregos e de estímulos à economia local. Entretanto, pode também gerar impactos negativos para o meio ambiente com o agravamento do desmatamento - e para a sociedade - com o deslocamento de populaçóes e a perda da cultura local. As diretrizes formuladas pelo projeto buscam mitigar os impactos socioambientais negativos e democratizar os benefícios econômicos.

Para aprofundar o conhecimento dos temas tratados e estimular a discussáo, os seguintes textos de apoio podem ser utilizados: (a) o relatório "Nosso futuro comum", da Comissáo Brundtland, que fornece uma definição amplamente disseminada de desenvolvimento sustentável (Brundtland, 1987); (b) o artigo "Partnerships from cannibals with forks: The triple bottom line of 21st-century business", de Elkington (1998), autor responsável por cunhar o termo "três pilares da sustentabilidade" (Triple Bottom Line - TBL); e (c) o documento da ONU "Objetivos de Desenvolvimento Sustentável (ODS)”. (United Nations [UN], 2020).

O debate sobre gestão de partes interessadas e engajamento de atores sociais pode ser conduzido a partir do desafio enfrentado pelos 'personagens' na transição entre as experiências de projetos anteriores na regiáo amazônica e a decisão de criar o novo projeto, focado na elaboraçáo das diretrizes.

Com a decisão pela realização de um projeto mais amplo, Daniela e Hector se viram diante da necessidade de gerir um grupo maior de partes interessadas, com maior diversidade e, potencialmente, mais conflitos. A tecnologia social adotada no projeto visou a enfrentar a complexidade do desafio.

Para facilitar a discussão nesse tema, os seguintes materiais de apoio podem ser utilizados: (a) "A stakeholder approach to strategic management", de Freeman e McVea (2001), cujo texto apresenta o conceito de gestáo de grupos de interesse; e (b) "Toward a theory of stakeholder identification and salience: Defining the principle of who and what really counts", de Mitchell, Agle e Wood (1997), cujo texto oferece orientação para a identificação e classificação de grupos de interesse.

$\mathrm{O}$ instrutor pode também indicar como leitura complementar o relatório completo do projeto "Grandes Obras na Amazônia: Aprendizados e Diretrizes", de
Ang e Monzoni (2017). A leitura ajudará os estudantes a se familiarizarem com o conteúdo das diretrizes e o seu processo de elaboração.

\section{QUESTÕES SUGERIDAS PARA OS ESTUDANTES}

No início da sessão, o instrutor pode buscar conexão com o caso, a partir das questóes de imersão 1 e 2:

1. Quais os impactos positivos e negativos gerados na regiáo amazônica pela implantação de grandes empreendimentos?

2. Quais grupos de interesse podem ser afetados por grandes empreendimentos na regiáo amazônica?

Em seguida, o instrutor pode utilizar duas 'questóes de transição', visando a estimular os estudantes a refletir sobre o desenvolvimento do projeto e seus dilemas:

3. Quais foram os principais fatores que levaram ao desenvolvimento do projeto "Grandes Obras na Amazônia: Aprendizados e Diretrizes"?

4. Quais foram os principais desafios enfrentados para a elaboração das diretrizes? Como foram tratados?

Finalmente, o instrutor pode indicar duas 'questóes de definição' sobre a implantação das diretrizes e enfrentar os principais dilemas do caso:

5. Como potencializar a efetiva aplicação das diretrizes?

6. Qual deve ser o foco de atuação após a divulgação das diretrizes: o fomento à sua aplicação no Brasil ou sua disseminação em outros países da regiáo amazônica?

\section{PLANO DE ENSINO}

No início da aula, o instrutor deve estimular o processo indutivo em sala e promover o engajamento dos estudantes com o tema. A discussão pode ser iniciada com algumas questóes gerais que permitam uma conexão entre o tema e os estudantes, seguidas de outras, que permitam retomar brevemente os conceitos fundamentais que nortearão a análise do caso:

(a) $\mathrm{O}$ que vocês entendem por desenvolvimento sustentável?

(b) Vocês acreditam que o tema se transformou em mero clichê ou está finalmente sendo levado a sério?

(c) O que é o tripé da sustentabilidade?

(d) $\mathrm{O}$ que significa gestão das partes interessadas?

(e) Como esses conceitos se relacionam ao caso? 
As seguintes referências podem servir de apoio ao instrutor: Elkington (1998) e Freeman e McVea (2001).

Após essa abertura, o instrutor deve levar os estudantes a compreender o contexto social e econômico que envolve os grandes empreendimentos na Amazônia. Em seguida, deve explorar as questôes específicas relacionadas à primeira fase do projeto. Finalmente, deve fomentar a reflexão sobre as definiçốes essenciais relacionadas à implantação das diretrizes.

\section{Quais os impactos positivos e negativos gerados na região amazônica pela implantação de grandes empreendimentos?}

Essa questão é direta e permite explorar os impactos dos grandes empreendimentos. Os estudantes devem ser capazes de identificar possíveis impactos. $\mathrm{O}$ instrutor pode ajudá-los a classificar cada um conforme o tripé da sustentabilidade. Uma sugestão de impactos - positivos e negativos - e respectivas classificaçóes pode ser vista no plano de quadro a seguir (Tabela 1).

Para estimular o debate, o instrutor pode dividir os estudantes em dois grupos, cada um defendendo posiçóes distintas. A primeira, de base preservacionista, defende que os recursos naturais devem ser preservados intactos. A segunda, de base conservacionista, procura combinar desenvolvimento econômico e sustentabilidade. Essa segunda posição é mais próxima da definiçáa de desenvolvimento sustentável dominante, presente nos Objetivos de Desenvolvimento Sustentável (ODS) da ONU.

Para facilitar o tratamento dessa questáo, o instrutor pode se apoiar nos conceitos de desenvolvimento sustentável e tripé da sustentabilidade, com base nas seguintes referências: Ambec e Lanoie (2008), Broman e Robèrt (2017), Brundtland (1987) e Elkington (1998).

Tabela 1. Plano de quadro 1.

\begin{tabular}{|c|c|c|c|c|c|}
\hline \multicolumn{2}{|c|}{ Impactos econômicos } & \multicolumn{2}{|c|}{ Impactos sociais } & \multicolumn{2}{|c|}{ Impactos ambientais } \\
\hline Positivos & Negativos & Positivos & Negativos & Positivos & Negativos \\
\hline $\begin{array}{l}\text { Aumento da renda } \\
\text { local }\end{array}$ & $\begin{array}{l}\text { Dependência da } \\
\text { renda ligada ao } \\
\text { empreendimento }\end{array}$ & Geração de empregos & $\begin{array}{l}\text { Deslocamento de } \\
\text { populaçóes }\end{array}$ & $\begin{array}{l}\text { Supressão vegetal } \\
\text { autorizada e controlada }\end{array}$ & $\begin{array}{l}\text { Desmatamento e } \\
\text { poluiçáo }\end{array}$ \\
\hline
\end{tabular}

\section{Quais grupos de interesse podem ser afetados por grandes empreendimentos na região amazônica?}

Essa questão permite ao instrutor introduzir o conceito de grupo de interesse e discutir como grupos de interesse podem influenciar ou condicionar decisóes que os afetam.

Os estudantes devem ser capazes de apontar as principais partes interessadas presentes no caso: os diversos grupos populacionais; as associaçóes locais e ONGs relacionadas à preservação da fauna e da flora; as empresas; e as organizaçóes governamentais.
O instrutor pode também incentivar os estudantes a identificar os objetivos de alguns grupos de interesse e construir, a partir dessas informaçóes, um esquema, conforme o plano de quadro a seguir (Tabela 2).

$\mathrm{O}$ instrutor pode ainda incentivar os estudantes a localizar os principais pontos de conflito entre grupos de interesse. Em seguida, o instrutor pode deslocar a discussão para questôes mais diretamente relacionadas ao projeto.

Para facilitar o tratamento dessa questão, o instrutor pode se apoiar no conceito de gestão das partes interessadas, com base nas seguintes referências: Freeman (2009); Freeman e McVea (2001), Mitchell et al. (1997).

Tabela 2. Plano de quadro 2.

\begin{tabular}{ll}
\hline \multicolumn{1}{c}{ Partes interessadas } & Objetivos \\
\hline Empresas de engenharia e construção & Reduzir risco de negócios e paralização de obras \\
Associações de proteção ambiental & Mitigar impacto ambiental e garantir perenidade das medidas \\
Populaçóes ribeirinhas & Garantir benefício econômico sustentável \\
Povos indígenas & Preservar território, cultura e modo de vida \\
Organizações governamentais & Melhorar indicadores econômicos e sociais \\
\hline
\end{tabular}




\section{Quais foram os principais fatores que levaram ao desenvolvimento do projeto "Grandes Obras na Amazônia: Aprendizados e Diretrizes"?}

A discussão dessa questâo permite compreender a iniciativa do FGV ces e da IFC frente ao contexto identificado e discutido nas questóes anteriores.

Os estudantes devem ser capazes de demonstrar seu entendimento sobre o ambiente que envolve o projeto e de identificar os fatores que levaram ao seu desenvolvimento, conforme o plano de quadro a seguir (Tabela 3).

$\mathrm{O}$ instrutor deve fomentar a compreensão de que o FGVces e a IFC atuaram como facilitadores de um processo econômico-social de alta complexidade, que se encontrava parcialmente bloqueado pela comunicaçáo deficiente entre atores sociais.

Para encaminhar o tratamento dessa questão, o instrutor pode se apoiar no documento principal do projeto: Ang e Monzoni (2017).

Tabela 3. Plano de quadro 3.

Fatores que levaram ao desenvolvimento do projeto

Alto potencial da região, em termos de riqueza de recursos hídricos e minerais

Discrepância entre o potencial da região e seus indicadores de desenvolvimento econômico e humano

Histórico de impacto negativo de grandes empreendimentos na região sobre as populaçôes locais

Metas de desenvolvimento do governo brasileiro e dos governos estaduais, assim como de múltiplas organizaçóes governamentais presentes na região

Objetivos de empresas de engenharia e construção, mineradoras e de grupos econômicos, interessados em investir na região

Objetivos e experiência do FGVces e da IFC na região

\section{Quais foram os principais desafios enfrentados para a elaboração das diretrizes? Como foram tratados?}

Essa questão permite tratar dois desafios enfrentados por iniciativas que envolvem múltiplos grupos de interesse, com focos eventualmente conflitantes. Os estudantes devem ser capazes de identificar os principais desafios e descrever como foram enfrentados pela equipe de trabalho.

O caso permite identificar dois grandes desafios e suas respectivas sugestóes, conforme o plano de quadro a seguir (Tabela 4).
O instrutor deve estimular os estudantes a perceber a necessidade de a equipe de trabalho ter grande sensibilidade social, de ser capaz de facilitar a interação produtiva entre grupos com interesses diversos e, frequentemente, conflitantes.

O instrutor deve também estimular os estudantes a perceber a importância da criação de um ambiente neutro e cooperativo, facilitado por agentes considerados competentes e legítimos (o FGVces e a IFC), para que o trabalho se desenvolvesse.

Para facilitar o tratamento dessa questáo, o instrutor pode se apoiar no documento principal do projeto: Ang e Monzoni (2017).

Tabela 4. Plano de quadro 4.

\begin{tabular}{|c|c|}
\hline Desafios & Soluçōes \\
\hline $\begin{array}{l}\text { Tratar uma situação complexa, envolvendo múltiplas dimensóes e diversas } \\
\text { partes interessadas }\end{array}$ & $\begin{array}{l}\text { A equipe do FGVces e da IFC empregou princípios de tecnologia social } \\
\text { que levaram à criação de seis linhas de ação, as quais definiram grupos de } \\
\text { trabalho e nortearam o desenvolvimento do projeto }\end{array}$ \\
\hline $\begin{array}{l}\text { Alinhar os interesses de múltiplos grupos, com origens, visóes e ideologias } \\
\text { distintas }\end{array}$ & $\begin{array}{l}\text { A equipe do FGVces e da IFC utilizou práticas de tecnologia social, com } \\
\text { intensa participação dos grupos de interesse, transparência da informação } \\
\text { e diversidade de formatos de interação, as quais incluíram reuniōes e semi- } \\
\text { nários }\end{array}$ \\
\hline
\end{tabular}




\section{Como potencializar a efetiva aplicação das diretrizes?}

Conforme visto no tratamento da questão anterior, o FGVces e a IFC apostaram na colaboraçáo e no engajamento dos atores sociais, por meio do uso de tecnologia social (distintos tipos de seminários, consulta pública, compartilhamento de estudos e relatórios, disseminação de relatórios em diferentes formados).

Essa, entretanto, não é a única abordagem possível para tratar o problema enfrentado. As duas organizaçóes poderiam, por exemplo, ter realizado esforços de advocacy visando a fomentar mudanças institucionais que regulassem mais estritamente investimentos produtivos na regiáo amazônica.
O instrutor pode, por exemplo, criar dois grupos e estimulá-los a defender duas posiçôes, uma mais alinhada com a opção adotada pelo FGVces e pela IFC, e outra, alternativa, priorizando o trabalho de advocacy junto a tomadores de decisão e reguladores. $\mathrm{O}$ plano de quadro a seguir (Tabela 5) pode ser utilizado para facilitar a comparação.

Após o debate, o instrutor pode fazer um fechamento, explicando que as duas alternativas não são necessariamente excludentes, e uma composição das duas poderia ter sido adotada.

Para facilitar o tratamento dessa questão, o instrutor pode se apoiar no conceito de gestáo das partes interessadas, com base nas seguintes referências: Freeman (2009), Freeman e McVea (2001), Mitchell et al. (1997).

Tabela 5. Plano de quadro 5.

\begin{tabular}{|c|c|c|c|}
\hline \multicolumn{2}{|c|}{ Engajamento de atores sociais } & \multicolumn{2}{|c|}{ Advocacy junto a reguladores } \\
\hline Vantagens & Desvantagens & Vantagens & Desvantagens \\
\hline $\begin{array}{l}\text { Engajamento gera produto que } \\
\text { representa o conjunto de atores } \\
\text { sociais envolvidos. }\end{array}$ & $\begin{array}{l}\text { Produto final pode ser influenciado } \\
\text { por assimetrias de poder. }\end{array}$ & Mudanças na regulação podem & $\begin{array}{l}\text { Aplicação efetiva do quadro } \\
\text { regulatório pode não ocorrer, por }\end{array}$ \\
\hline $\begin{array}{l}\text { Mobilização gera ganhos paralelos, } \\
\text { tais como a redução de conflitos } \\
\text { entre as partes interessadas. }\end{array}$ & $\begin{array}{l}\text { Mudanças nas partes interessadas } \\
\text { podem afetar o comprometimento } \\
\text { em médio e longo prazos. }\end{array}$ & $\begin{array}{l}\text { as partes interessadas a agirem de } \\
\text { acordo. }\end{array}$ & $\begin{array}{l}\text { não adesão das partes interessadas } \\
\text { ou dificuldades para monitoramento } \\
\text { e controle. }\end{array}$ \\
\hline
\end{tabular}

\section{Qual deve ser o foco de atuação} após a divulgação das diretrizes: o fomento à sua aplicação no Brasil ou sua disseminação em outros países da região amazônica?

Essa questão final trata de um aspecto crucial, presente neste caso e em muitos outros: como passar do planejamento para a execução, ou, em outras palavras, como garantir que o que foi planejado seja bem executado e atinja os objetivos esperados.
O caso termina justamente no lançamento das diretrizes, momento marcado por grandes esperanças e expectativas. Porém, também marcado por alguns pontos de atenção. Suspeita-se, por exemplo, que a extensão ou amplitude dificulte sua absorção e uso, principalmente por empresas e órgãos de governo.

O instrutor deve estimular os estudantes a identificar barreiras e riscos à implantação, e a desenvolver estratégias para enfrentá-los. O plano de quadro a seguir (Tabela 6) pode ser utilizado para facilitar a análise.

Tabela 6. Plano de quadro 6.

\begin{tabular}{|c|c|}
\hline Barreiras e riscos & Estratégias para enfrentá-los \\
\hline Entrada de novas organizações na região & $\begin{array}{l}\text { Criaçáo de uma associação que envolva todas as partes interessadas e que } \\
\text { tenha como foco de atuaçáo a atraçáo e o alinhamento de novas organizaçôes } \\
\text { que possam surgir }\end{array}$ \\
\hline Mudanças na constituição das partes interessadas & $\begin{array}{l}\text { Estímulo às partes interessadas para que institucionalizem as diretrizes na } \\
\text { forma de normas e práticas }\end{array}$ \\
\hline Mudanças nas políticas públicas & $\begin{array}{l}\text { Realização de um movimento contínuo de influência sobre as diversas } \\
\text { esferas de poder público, visando à manutençãao dos princípios básicos que } \\
\text { sustentam as diretrizes }\end{array}$ \\
\hline
\end{tabular}


$\mathrm{O}$ instrutor deve também estimular os estudantes a identificar as vantagens e desvantagens da ampliação do projeto para outros países da região amazônica. Será tal iniciativa capaz de ajudar a consolidar o esforço iniciado no Brasil ou resultará em dispersão de esforços, os quais deveriam ser focados na implementação das diretrizes no Brasil? O plano de quadro a seguir (Tabela 7 ) pode ser utilizado para avaliar os dois caminhos.

Após o debate, o instrutor pode fazer um fechamento, mencionando que, mais uma vez, as duas alternativas não são necessariamente excludentes, e uma composição das duas poderia ser adotada.

No final, o instrutor pode prover um sumário do caso, revisando desde os aspectos de contexto até a questão da implantação das diretrizes. Poderá também registrar, junto com os estudantes, as principais liçôes aprendidas, relacionando cada uma delas aos temas do caso: três pilares da sustentabilidade, gestão de partes interessadas e engajamento de atores sociais.

Tabela 7. Plano de quadro 7.

\begin{tabular}{|c|c|c|c|}
\hline \multicolumn{2}{|c|}{ Implantação das diretrizes no Brasil } & \multicolumn{2}{|c|}{ Transposição das diretrizes para outros países } \\
\hline Vantagem & Desvantagem & Vantagem & Desvantagem \\
\hline $\begin{array}{l}\text { Maximização do potencial } \\
\text { de esforços, dado o histórico } \\
\text { já construído, as relaçóes já } \\
\text { estabelecidas e o conhecimento do } \\
\text { contexto brasileiro }\end{array}$ & $\begin{array}{l}\text { Impacto positivo do projeto fica } \\
\text { restrito apenas à Amazônia brasileira }\end{array}$ & $\begin{array}{l}\text { Ampliação do impacto positivo do } \\
\text { projeto a toda região amazônica }\end{array}$ & $\begin{array}{l}\text { Risco de enfrentar dificuldades } \\
\text { ou mesmo falha, em função do } \\
\text { conhecimento restrito do contexto } \\
\text { e das partes interessadas que atuam } \\
\text { em outros países }\end{array}$ \\
\hline
\end{tabular}

\section{O QUE ACONTECEU DEPOIS}

Para fechar a sessão, o instrutor pode mencionar os desdobramentos do caso. Aproximadamente três anos após o lançamento das diretrizes, Daniela informou a realização de três novas iniciativas, que são consequência do projeto: primeiro, a revisáo do modelo de governança territorial em uma usina hidrelétrica já instalada na Amazônia; segundo, a criação de um laboratório de políticas públicas para a regiấo; e terceiro, um projeto de desenvolvimento sustentável, associado à pavimentação de uma rodovia.
Além dessas iniciativas, Daniela citou a aplicação das diretrizes a um projeto de instalação de uma mineradora no Peru. Essas quatro iniciativas constituem evidências da adoção das diretrizes e de impactos positivos da tecnologia social utilizada. Entretanto, em sua declaração, Daniela evidenciou um dos desafios essenciais que enfrenta a regiāo: equilibrar a justa expectativa de suas populaçóes, de melhora de suas condições materiais e da qualidade de vida, sem comprometer o meio ambiente e o futuro de geraçóes vindouras. 
Tabela 8. Planejamento de tempo de aula.

\begin{tabular}{|c|c|c|}
\hline $\begin{array}{c}\text { Tempo } \\
\text { (min) }\end{array}$ & Tópico & $\begin{array}{c}\text { Hora de } \\
\text { início }\end{array}$ \\
\hline \multicolumn{3}{|c|}{ INTRODUÇÃO } \\
\hline 15 & $\begin{array}{l}\text { a. O que vocês entendem por desenvolvimento sustentável? } \\
\text { b. Vocês acreditam que o tema se transformou em mero clichê ou está finalmente sendo levado a sério? } \\
\text { c. O que é o tripé da sustentabilidade? } \\
\text { d. O que significa gestáo das partes interessadas? } \\
\text { e. Como esses conceitos se relacionam ao caso? }\end{array}$ & \\
\hline
\end{tabular}

\title{
CONTEXTO
}

20

Análise de impactos

Q1: Quais os impactos positivos e negativos gerados na região amazônica pela implantação de grandes empreendimentos?

20

Gestão de partes interessadas

Q2: Quais grupos de interesse podem ser afetados por grandes empreendimentos na regiáo amazônica?

\section{DESENVOLVIMENTO DO PROJETO}

10 Q3: Quais foram os principais fatores que levaram ao desenvolvimento do projeto "Grandes Obras na Amazônia: Aprendizados e Diretrizes"?

20 Desafios

Q4: Quais foram os principais desafios enfrentados para a elaboração das diretrizes? Como foram tratados?

\section{IMPLEMENTAÇÃO DO PROJETO}

Dilema 1: condiçóes de base para implementaçáo

Q5: Como potencializar a efetiva aplicação das diretrizes?

20

Dilema 2: prioridade de implementaçáo

Q6: Qual deve ser o foco de atuação após a divulgação das diretrizes: o fomento à sua aplicação no Brasil ou sua disseminação em outros países da regiáo amazônica?

\section{CONCLUSÃO}

15

\author{
Sumário \\ Quais foram as principais liçōes aprendidas?
}

\section{REFERÊNCIAS}

Ambec, S., \& Lanoie, P. (2008). Does it pay to be green? A systematic overview. Academy of Management Perspectives, 22(4), 4562. https://doi.org/10.5465/amp.2008.35590353

Ang, H. G., \& Monzoni, M. (2017). Grandes obras na Amazônia: Aprendizados e diretrizes. Sáo Paulo: FGVces \& IFC. Retrieved from https://bibliotecadigital.fgv.br/dspace/handle/10438/18320

Broman, G. I., \& Robèrt, K.-H. (2017). A framework for strategic sustainable development. Journal of Cleaner Production, 140(Part 1), 17-31. https://doi.org/10.1016/j.jclepro.2015.10.121

Brundtland, G. H. (1987). Our common future - Call for action. Environmental Conservation, 14(4), 291-294. https://doi.org/10.1017/S0376892900016805
Elkington, J. (1998). Partnerships from cannibals with forks: The triple bottom line of 21 st-century business. Environmental Quality Management, 8(1), 37-51. https://doi.org/10.1002/tqem.3310080106

Freeman, R. E. (2009) What is Stakeholder Theory? Retrieved from https://www.youtube.com/watch?v=bIRUaLcvPe8

Freeman, R. E., \& McVea, J. (2001). A stakeholder approach to strategic management. Retrieved from http://faculty.wwu. edu/dunnc3/rprnts.stakeholderapproach.pdf

Mitchell, R. K., Agle, B. R., \& Wood, D. J. (1997). Toward a theory of stakeholder identification and salience: Defining the principle of who and what really counts. Academy of Management Review, 22(4), 853-886. https://doi.org/10.5465/amr.1997.9711022105

United Nations (2020). Sustainable Development Goals. Retrieved from http://www.un.org/sustainabledevelopment/ sustainable-development-goals/ 


\section{Autoria}

\section{Thomaz Wood Jr.*}

Fundação Getulio Vargas, Escola de Administração de Empresas de São Paulo (FGV EAESP)

Av. Nove de Julho, no 2029, Bela Vista, 01313 902, São Paulo, SP, Brasil

E-mail: thomaz.wood@fgv.br

(D) https://orcid.org/0000-0002-5610-4699

\section{Dafne Oliveira Carlos de Morais}

Centro Universitário FEI

Rua Tamandaré, no 688, Liberdade, 01525-000, São Paulo, SP, Brasil

E-mail: dafne.morais@fei.edu.br

(D) https://orcid.org/0000-0001-9188-7900

* Autor Correspondente

\section{Financiamento}

Os autores agradecem à FGV/EAESP Pesquisa pelo apoio financeiro concedido no Projeto "Casos de Impacto Social" 2017-1.

\section{Conflito de Interesses}

Os autores informaram que não há conflito de interesses.

\section{Verificação de Plágio}

A RAC mantém a prática de submeter todos os documentos aprovados para publicação à verificação de plágio, mediante o emprego de ferramentas específicas, e.g.: iThenticate.

\section{Contribuiç̧ões dos Autores}

1 autor: conceituação (liderança); aquisição de financiamento (liderança); metodologia (liderança); administração de projeto (liderança); supervisão (liderança); escrita - rascunho original (suporte); escrita - revisão e edição (igual).

2a autora: curadoria de dados (liderança); investigação (liderança); escrita - rascunho original (liderança); escrita revisão e edição (igual).

\section{Direitos Autorais}

A RAC detém os direitos autorais deste conteúdo.

\section{Método de Revisão por Pares}

Este conteúdo foi avaliado utilizando o processo de revisão por pares duplo-cego (double-blind peer-review). A divulgação das informaçôes dos pareceristas constantes na primeira página é feita somente após a conclusấo do processo avaliativo, e com o consentimento voluntário dos respectivos pareceristas.

\section{Disponibilidade dos Dados}

A RAC incentiva o compartilhamento de dados mas, por observância a ditames éticos, não demanda a divulgação de qualquer meio de identificação de sujeitos de pesquisa, preservando a privacidade dos sujeitos de pesquisa. A prática de open data é viabilizar a reproducibilidade de resultados, e assegurar a irrestrita transparência dos resultados da pesquisa publicada, sem que seja demandada a identidade de sujeitos de pesquisa. 